Tropical Journal of Pharmaceutical Research February 2020; 19 (2): 299-304

ISSN: $1596-5996$ (print); 1596-9827 (electronic)

(C) Pharmacotherapy Group, Faculty of Pharmacy, University of Benin, Benin City, 300001 Nigeria.

\title{
Protective effect of ethosuximide on hearing in NOD/LtJ mice via blockage of endogenous apoptosis
}

\author{
Dejun Zhang, Guofang Guan*, Yingyuan Guo, Yanru Hao, Fang Guo, Zeming \\ Fu \\ Department of Otolaryngology, Head and Neck Surgery, The Second Hospital of Jilin University, Changchun, PR China \\ *For correspondence: Email: g779hy@163.com
}

Sent for review: 8 November 2019

Revised accepted: 27 January 2020

\begin{abstract}
Purpose: To determine the protective effect of ethosuximide on the hearing of NOD/LIJ mice, and the underlying mechanism of action.

Methods: The mice were randomly assigned to control and treatment groups (20 mice per group). Mice in the treatment group were administered ethosuximide intraperitoneally at a dose of $200 \mathrm{mg} / \mathrm{kg}$ body weight (bwt), while those in the control group received an equivalent dose of saline via the same route. $B$ Both groups were subjected to auditory brainstem response (ABR) and distortion product otoacoustic emissions (DPOAE) tests, as well as determination of mRNA expressions of $\alpha 1 \mathrm{G}, \alpha 1 \mathrm{H}, \alpha 1 \mathrm{l}, \mathrm{m}$-calpain, $\mu$-calpain, and caspase-3.

Results: At ages of 6 and 9 weeks, ABR values were significantly lower in the treatment group than those in the control group $(p<0.05)$. At age 3, 6 and 9 weeks, control group DPOAE values were much lower than those in the treatment group. However, at signal frequency of $35344 \mathrm{~Hz}$, DPOAE value was significantly reduced in the treatment group $(p<0.05)$. There was significant down-regulation in mRNA expressions of $\alpha 1 G, a 1 H, a 11, m$-calpain, $\mu$-calpain and caspase-3, in the treatment group, when compared with the control group $(p<0.05)$.

Conclusion: Ethosuximide delays mice hearing loss and protects their hearing via a mechanism involving blockage of endogenous apoptotic pathways. This mechanism may provide guidance in the search for suitable new drugs.
\end{abstract}

Keywords: Ethosuximide, Endogenous apoptosis, Hearing, Protection

\begin{abstract}
This is an Open Access article that uses a fund-ing model which does not charge readers or their institutions for access and distributed under the terms of the Creative Commons Attribution License (http://creativecommons.org/licenses/by/4.0) and the Budapest Open Access Initiative (http://www.budapestopenaccessinitiative.org/read), which permit unrestricted use, distribution, and reproduction in any medium, provided the original work is properly credited.
\end{abstract}

Tropical Journal of Pharmaceutical Research is indexed by Science Citation Index (SciSearch), Scopus, International Pharmaceutical Abstract, Chemical Abstracts, Embase, Index Copernicus, EBSCO, African Index Medicus, JournalSeek, Journal Citation Reports/Science Edition, Directory of Open Access Journals (DOAJ), African Journal Online, Bioline International, Open-J-Gate and Pharmacy Abstracts

\section{INTRODUCTION}

Pathological changes in the auditory nerve and the central nervous system which are involved in the conduction of auditory signals lead to hearing impairments collectively referred to as deafness [1]. Based on the nature of lesion, deafness is divided into conductive deafness, sensorineural deafness, mixed deafness and central deafness. Sensorineural deafness comprises several kinds of deafness such as congenital deafness, acquired deafness, senile deafness, and traumatic deafness [2]. Senile deafness is one of the most common sensory dysfunctions in the world. 
According to audiology studies, men begin to experience hearing loss from the age of 45 , while women experience it later. With advances in medical technology, humans now live longer than before, but the incidence of senile deafness is on the rise due to ageing population [3]. The NOD/LtJ mice are ideal for use as experimental model of senile deafness. These mice preserve intact hearing at birth, but hearing loss occurs about 3 weeks after birth, with severe deafness at about 13 weeks of age. Some scholars have found that anti-epileptic drugs that block T-type calcium channels reduce hearing loss due to noise-induced deafness [4]. Apoptosis, also known as programmed cell death, is a natural and physiological process. Apoptosis leads to cochlear cell damage, and decreases the number of cochlear cells. It has been suggested that the greatest potential threat of intracellular high calcium concentration is due to the activation of calpain activity, which is often an early signal of apoptosis, degeneration and necrosis [5]. It is thought that an important factor causing senile deafness is disorder in $\mathrm{Ca}^{2+}$ homeostasis. Disorder in intracellular $\mathrm{Ca}^{2+}$ homeostasis is induced by activation of calpain and its downstream caspase family. Ethosuximide is the drug of first choice for treating minor epilepsy; it blocks T-type calcium channels, thus conferring protection from senile deafness [6]. In this study, NOD/LtJ mice were used to investigate the mechanism involved in the protection of hearing by ethosuximide.

\section{EXPERIMENTAL}

\section{Animals}

A total of 40 healthy NOD/LtJ mice provided by Guangzhou Saibo Biotechnology Co. Ltd. [production license SCXK (Yue) 2017-0001)] were used. The mice had mean body weight of $25 \pm 10 \mathrm{~g}$, and were aged $4-20$ weeks. They were bred in the experimental room with 12-h light/12-h darkness at average temperature of 25 $\pm 2{ }^{\circ} \mathrm{C}$ and relative humidity of $45 \pm 15 \%$.

This research was approved by the Animal Ethical Committee of Department of Otolaryngology, Head and Neck Surgery, The Second Hospital of Jilin University, Changchun, PR China (approval no. 201822385) and performed according to "Principles of Laboratory Animal Care" (NIH publication no. 85-23, revised 1985) [7].

\section{Main equipment and reagents}

The major instruments and reagents used, and their suppliers (in brackets) were: optical microscope (Beijing Zhongxi Yuanda Technology Co. Ltd, model: TS2009); low temperature refrigerator (Wuxi Haoze Physical and Chemical Equipment Co. Ltd, model no. GY-8050N); constant temperature water bath (Shanghai Hetian Scientific Instrument Co. Ltd, model no. $\mathrm{HH}-501 \mathrm{~S}$ ); centrifuge (Beckman Coulter, USA, Model: Avanti JXN-30/26); electronic balance (Shandong Changou Trading Co. Ltd, Specification: HZ-A50001) and heating thermostat mixer (Shanghai Kesheng Instrument) Co. Ltd, Model: DF-101S). The others were PCR Amplifier (Shanghai Baqi Industrial Co. Ltd, Model: T100); PCR Primer (Shanghai Thermo Fisher Scientific Co. Ltd); xylene (Zhang Runxin Chemical Zone, Zhangjiagang Free Trade Zone) Trading Co. Ltd; anhydrous ethanol (National Pharmaceutical Group Chemical Reagent Co. Ltd), and ethosuximide (Wuhan Yuanda Pharmaceutical Group Co. Ltd, approval number: National Pharmaceutical Standard H31020192, specification: $0.25 \mathrm{~g}$ ).

\section{Animal grouping and establishment of animal model}

NOD/LtJ mice were housed in a low-noise environment and tested for their different responses to sound stimulation every 3 weeks. Two groups of mice were generated: control and treatment groups, using the random number table method, with 20 mice per group. Mice in the observation group were intraperitoneally injected with ethosuximide at a dose of $200 \mathrm{mg} / \mathrm{kg} \mathrm{bwt}$, while control mice were given an equivalent dose of normal saline via the same route. Dosing of all mice started at week 3 , and their body weights were measured daily for dose adjustment. Their mental states were closely observed.

The mice were intraperitoneally anesthetized and fixed on the operation table. During the experiment, temperature was maintained at 37 ${ }^{\circ} \mathrm{C}$. Brainstem auditory evoked potential instrument was used in the experiment. The scalp needle of recording electrode was inserted in the cranial skin of each mouse, while the reference electrode was inserted in the skin beneath the enation of the test ear. The grounding electrode was connected to the contralateral enation. The stimulus sound output earphone of the brainstem evoked auditory potential meter was placed in the ear canal of the mice, and short sound, 8,16 , and $32 \mathrm{kHz}$ were used as pure tone stimuli. The average number of times of electric potential superposition was set to 1024, and the scanning time was $10 \mathrm{~min}$. The minimum stimulation intensity corresponding to the waveform of distinguishable $A B R$ was taken as the threshold value. 
On completion of the ABR test, the mice were subjected to DPOAE test to evaluate the functionality of hair cells. The mice were placed in a soundproof chamber. A probe of appropriate size was placed in the external auditory canal of each mouse, and two different sensors were selected according to the magnitude of the stimulation frequency. The $\mathrm{ABR}$ and DPOAE tests were performed at 3,6 , and 9 weeks of age.

On completion of ABR and DPOAE tests at the 9th week, 10 mice in each group were sacrificed. Their cochleae were excised, and unwanted tissues were removed prior to fixing the cochlea in $4 \%$ formaldehyde solution. The cochlear specimens were taken out after fixation, followed by removal of formaldehyde via blotting with filter paper. The specimens were washed 3 times in phosphate buffer solution, and decalcified in decalcification solution for 1 week, before they were kept in a $4{ }^{\circ} \mathrm{C}$ refrigerator. The cochlea was completely stripped under a dissecting microscope, and excess connective tissues were removed. The basement membrane of the base gyrus, the middle gyrus and the apex gyrus of cochlea were separated and placed on a glass slide, and the excess tissues were washed away. The F-actin of the hair cell cilia was stained with phalloidin so as to observe the shedding of the cochlear hair cell under a microscope.

Cochlear specimens from the two groups of mice were subjected to dehydration, embedding in wax, and sectioning. Then, the sections were stained with hematoxylin and eosin $(H \& E)$, and the cochlear cells were examined under a light microscope.

\section{Determination of relative mRNA expressions of apoptosis genes}

The cochlear tissues were taken out from the refrigerator and $3 \mathrm{ml}$ Trizol reagent was added to separate the protein from the RNA. Then, the mixture was centrifuged in a pre-chilled centrifuge tube, and the supernatant was mixed with equal volume of $20 \%$ chloroform, and shaken vigorously until the solution became milky white. The solution was then centrifuged after standing, and the supernatant was diluted with equal volume of isopropanol and centrifuged. The precipitate was used for assay of the relative mRNA expressions of $\alpha 1 \mathrm{G}, \alpha 1 \mathrm{H}$, $\alpha 1 \mathrm{l}, \mathrm{m}$-calpain, $\mu$-calpain and caspase-3.

\section{Assessment of treatment indices}

The treatment indices assessed were $A B R$ and DPOAE, cochlear cell tissue structure, cochlear hair cell loss, and the mRNA expressions of $\alpha 1 \mathrm{G}$, $\alpha 1 \mathrm{H}, \alpha 1 \mathrm{l}, \mathrm{m}$-calpain, $\mu$-calpain and caspase-3 of mice in the two groups.

\section{Statistical analysis}

All data were analyzed using software SPSS 20.0. Measurement data were compared using independent sample $t$-test, while count data were compared using $\mathrm{x}^{2}$ test. Ranking data were compared using Ridit test. Differences were assumed to be statistically significant at $p<0.05$.

\section{RESULTS}

\section{$A B R$ values for mice}

The ABR values showed an upward trend in control treatment mice groups, but the degree of increase was higher in control mice. At 6 and 9 weeks of age, when the sound stimulation frequency values were click, 8,16 and $32 \mathrm{kHz}$, the ABR values were much lower in the observation group than in the control group ( $p<$ 0.05). These results are shown in Table 1.

\section{DPOAE values for mice}

At 3 weeks of age, when the stimulation signal frequencies were 4422, 8844, 12503, 17692 and $24990 \mathrm{~Hz}$, the DPOAE values were much lower in control than in treatment mice. At 6 weeks of age, when the stimulation signal frequencies were 4422, 17672, and $24990 \mathrm{~Hz}$, the DPOAE values were markedly lower in control mice. At 9 weeks of age, when the stimulation signal frequencies were 8844, 12503, and $17672 \mathrm{~Hz}$,

Table 1: ABR values for mice (mean \pm SD)

\begin{tabular}{|c|c|c|c|c|c|}
\hline Group & & Click (dB) & 8kHz(dB) & 16kHz(dB) & $32 \mathrm{kHz}(\mathrm{dB})$ \\
\hline \multirow{3}{*}{$\begin{array}{l}\text { Treatment } \\
(n=20)\end{array}$} & 3 weeks & $58.68 \pm 2.88$ & $68.26 \pm 3.54$ & $69.56 \pm 2.09$ & $79.51 \pm 4.28$ \\
\hline & 6 weeks & $63.29 \pm 2.87$ & $73.43 \pm 2.66$ & $77.28 \pm 3.46$ & $81.53 \pm 3.69$ \\
\hline & 9 weeks & $69.74 \pm 5.76$ & $76.23 \pm 5.87$ & $81.64 \pm 2.26$ & $93.19 \pm 6.95$ \\
\hline \multirow{3}{*}{$\begin{array}{l}\text { Control } \\
(n=20)\end{array}$} & 3 weeks & $59.53 \pm 2.14$ & $69.26 \pm 2.57$ & $70.21 \pm 1.57$ & $80.25 \pm 1.66$ \\
\hline & 6 weeks & $71.13 \pm 5.26$ & $81.09 \pm 1.41$ & $90.27 \pm 2.17$ & $89.35 \pm 2.45$ \\
\hline & 9 weeks & $85.32 \pm 2.79$ & $88.64 \pm 2.63$ & $93.49 \pm 1.92$ & $106.28 \pm .86$ \\
\hline
\end{tabular}


the DPOAE values were significantly lower in the control group than in the observation group. However, when the stimulation signal frequency was $35344 \mathrm{~Hz}$, the DPOAE value was markedly higher in control mice than in treatment mice $(p<$ 0.05).

\section{Changes in cochlear cell structure of mice}

In the control group, the spiral ganglion cells in the cochlea were disordered, with much reduction in number, condensed nuclei, agglutinated chromosomes, and numerous vacuoles. The loss of spiral ganglion cells in cochlea was markedly decreased in observation group, when compared with the control group. Cochlear hair cells in control group were atrophied and decreased in number, in contrast to the observation group, where they were in neat arrangement, with significantly lower hair cell loss. The loss of hair cells in cochlea was decreased in observation group, when compared with control group. These results are shown in Figure 1.
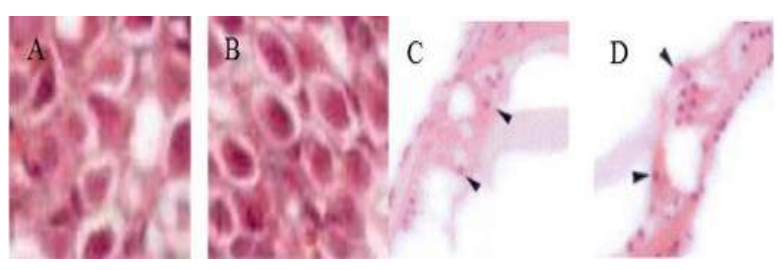

Figure 1: Changes in cochlear cell structure of the mice in the two groups. A: spiral ganglion cells in the cochlea of mice in the control group; B: spiral ganglion cells in the cochlea of the mice in the observation group; Figure C: cochlear hair cells in mice in control group; D: cochlear hair cells in mice in observation group

\section{Hair cell loss in mice}

Hair cell loss was much more reduced in treatment mice than in the control mice, as shown in Figure 2.

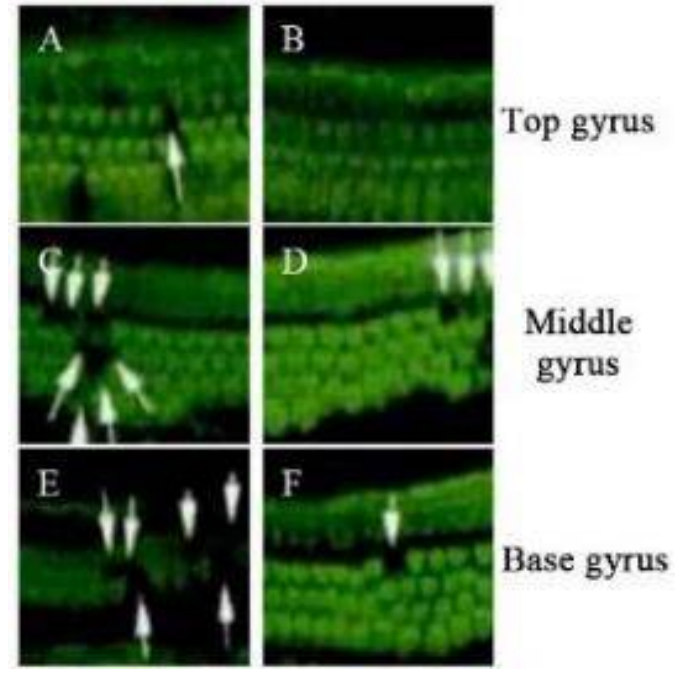

Figure 2: Comparison of hair cell loss in mice in the two groups. Hair cells in (A) cochlear top gyrus of mice in the control group; B: cochlear top gyrus of mice in the observation group; $\mathrm{C}$ : cochlear middle gyrus of mice in the control group; D: cochlear middle gyrus of mice in the observation group; $\mathrm{E}$ : cochlear base gyrus of mice in the control group; F: cochlear base gyrus of mice in the observation group

M-RNA expressions of $\alpha 1 \mathrm{G}, \alpha 1 \mathrm{H}, \alpha 1 \mathrm{l}, \mathrm{m}-$ calpain, $\mu$ - calpain and caspase- 3 of mice

Compared with the control group, the expressions of $\alpha 1 \mathrm{G}$ mRNA, $\alpha 1 \mathrm{H}$ mRNA, $\alpha 1 \mathrm{l}$ mRNA, m-Calpain mRNA, $\mu$-calpain mRNA and caspase-3 mRNA were decreased much more in the observation group $(p<0.05)$, as shown in Table 3.

\section{DISCUSSION}

Senile deafness is a common neurodegenerative disease. Clinically, progressive neurological deafness in the elderly is called senile deafness. As individuals age, a series of aging signs become manifest.

Table 2: DPOAE values for mice in the two groups (mean $\pm \mathrm{SD}, \mathrm{dB} S P L$ )

\begin{tabular}{|c|c|c|c|c|c|c|}
\hline \multirow{2}{*}{ Index } & \multicolumn{3}{|c|}{ Control group $(n=20)$} & \multicolumn{3}{|c|}{ Treatment group $(n=20)$} \\
\hline & 3 weeks & 6 weeks & 9 weeks & 3 weeks & 6 weeks & 9 weeks \\
\hline 4422 & $3.52 \pm 1.61$ & $5.03 \pm 1.69$ & $4.52 \pm 3.84$ & $5.62 \pm 2.13$ & $10.45 \pm 1.23$ & $4.52 \pm 3.84$ \\
\hline 6244 & $-2.77 \pm 3.15$ & $-2.54 \pm 3.97$ & $-1.26 \pm 2.59$ & $-5.21 \pm 6.37$ & $-2.46 \pm 3.98$ & $3.75 \pm 6.34$ \\
\hline 8844 & $2.14 \pm 2.13$ & $3.29 \pm 3.15$ & $1.02 \pm 2.26$ & $12.17 \pm 2.59$ & $3.32 \pm 3.11$ & $10.14 \pm 3.68$ \\
\hline 12503 & $5.06 \pm 0.65$ & $11.68 \pm 1.23$ & $11.65 \pm 2.33$ & $10.26 \pm 3.67$ & $11.73 \pm 1.19$ & $14.54 \pm 1.21$ \\
\hline 17672 & $3.82 \pm 1.27$ & $3.35 \pm 0.96$ & $3.64 \pm 1.17$ & $6.33 \pm 1.28$ & $7.77 \pm 2.38$ & $5.79 \pm 1.02$ \\
\hline 24990 & $15.25 \pm 2.52$ & $6.37 \pm 3.11$ & $15.24 \pm 2.49$ & $18.84 \pm 1.24$ & $15.49 \pm 2.11$ & $15.29 \pm 2.49$ \\
\hline 35344 & $-13.22 \pm 3.49$ & $-10.22 \pm 2.67$ & $-15.54 \pm 1.25$ & $-13.17 \pm 3.46$ & $-10.15 \pm 2.58$ & $-7.23 \pm 1.55$ \\
\hline
\end{tabular}


Table 3: mRNA expressions of $\alpha 1 \mathrm{G}, \alpha 1 \mathrm{H}, \alpha 1 \mathrm{l}, \mathrm{m}$-calpain, $\mu$-calpain and caspase-3 of mice in the two groups $\pm n$ $=10$ )

\begin{tabular}{lcccc}
\hline Index & Control group & Treatment group & $\boldsymbol{t}$ & $\boldsymbol{P}$-value \\
\hline a1G mRNA & $1.69 \pm 0.43$ & $1.26 \pm 0.21$ & 2.842 & 0.011 \\
a1H mRNA & $2.14 \pm 0.19$ & $1.03 \pm 0.08$ & 17.027 & $<0.001$ \\
a1I mRNA & $4.21 \pm 0.25$ & $1.37 \pm 0.39$ & 19.387 & $<0.001$ \\
m-Calpain mRNA & $1.53 \pm 0.27$ & $1.17 \pm 0.17$ & 3.568 & 0.002 \\
$\mu$ - Calpain mRNA & $2.05 \pm 0.33$ & $1.18 \pm 0.35$ & 5.719 & $<0.001$ \\
Caspase-3 mRNA & $2.96 \pm 0.12$ & $1.35 \pm 0.26$ & 17.779 & $<0.001$ \\
\hline
\end{tabular}

Senile deafness is an auditory dysfunction caused by the aging of the auditory system. Due to advances in medical science and technology, China is experiencing increases in aging population, and the incidence of senile deafness is increasing year by year. According to statistics, the probability of senile deafness in the elderly over 75 years old is above $55 \%$ in China [8]. Decline in hearing has a serious impact on the verbal communication ability of the elderly, leading to difficulty in communication with family and friends, thereby greatly increasing the risk of depression. Many factors predispose to senile deafness. These include intrinsic factors which consist of genetic factors and systemic factors. Apart from intrinsic factors, other factors involved are external factors such as environmental noise, smoking and drinking, exposure to ototoxic drugs and chemical agents, and infections. These factors damage the cochlear hair cells, and may cause or aggravate development of senile deafness. It is currently believed that senile deafness can be treated by promoting cochlear hair cell regeneration or reducing cochlear hair cell loss [9]. Studies have found that the hair cells in cochlea promote the release of neurotrophic substances and play an important role in the survival of spiral ganglion neurons [10].

The NOD/LtJ mouse model is characterized by rapid progression of hearing loss with age, which may be due to the fact that the cochlear hair cells and spiral ganglion cells of the mouse are gradually lost from the base gyrus to the top gyrus as the mice age. Therefore, the NOD/LtJ mouse model is currently the preferred animal model for studying senile deafness. Studies have shown that mutation in the 753A sub-allelic in the Cdh23 gene of NOD/LtJ mouse is responsible for defects in hearing function in NOD/LtJ mice [11]. Cadherin is a glycoprotein involved in $\mathrm{Ca}^{2+-}$ related cell adhesion and migration. Its adhesion or stability may alter the sensitivity of NOD/LtJ mice to senile deafness [12]. It has been reported that calcium-dependent cell adhesion has a serious impact on the integrity of cochlear cells [13]. The T-type $\mathrm{Ca}^{2+}$ channels regulate intracellular $\mathrm{Ca}^{2+}$, whether the cells are hair cells or spiral ganglion cells. The constituent subunits of the T-type $\mathrm{Ca}^{2+}$ channel are $\alpha 1 \mathrm{G}, \alpha 1 \mathrm{H}$, and a1l. In the results of this study, ethosuximide significantly reduced the expression levels of a1G mRNA, $\alpha 1 \mathrm{H}$ mRNA, and a1l mRNA, indicating that it specifically blocks T-type $\mathrm{Ca}^{2+}$ channels as well as neuronal apoptosis pathways.

An acoustic signal discovered by Kemp, DPOAE is emitted by the cochlea, and it retrogrades along the ossicular chain to the periosteum and the external auditory canal. Studies have found that the production of DPOAE is closely related to hair cell function [14]. Apoptosis is a series of gene-mediated changes. During endogenous apoptosis, a variety of cellular stress responses or apoptotic signals lead to the release of apoptosis-related genes by mitochondria. When they enter the cytoplasm, they bind to, and activate apoptosis protease activator-1, leading to simultaneous cascades of downstream caspase- 3 and caspase- 6 , which in turn leads to apoptosis [15]. In this study, ethosuximide markedly inhibited the expression of calpain, and prevented cell damage induced by calpain, thereby preventing the apoptosis of spiral ganglion cells and delaying the hearing loss of mice. These findings are consistent with the results of Fu et al [16].

\section{CONCLUSION}

Ethosuximide delays hearing loss in mice and protects their hearing through suppression of endogenous apoptotic pathways which may provide guidance in the search for suitable new drugs.

\section{DECLARATIONS}

\section{Conflict of interest}

No conflict of interest is associated with this work.

\section{Contribution of authors}

We declare that this work was done by the author(s) named in this article and all liabilities 
pertaining to claims relating to the content of this article will be borne by the authors. All authors read and approved the manuscript for publication. Guofang Guan conceived and designed the study, while Dejun Zhang, Guofang Guan, Yingyuan Guo, Yanru Hao, Fang Guo, Zeming $\mathrm{Fu}$ collected and analysed the data, Dejun Zhang wrote the manuscript.

\section{Open Access}

This is an Open Access article that uses a funding model which does not charge readers or their institutions for access and distributed under the terms of the Creative Commons Attribution License (http://creativecommons.org/licenses/by/ 4.0) and the Budapest Open Access Initiative (http://www.budapestopenaccessinitiative.org/rea d), which permit unrestricted use, distribution, and reproduction in any medium, provided the original work is properly credited.

\section{REFERENCES}

1. Marschark M, Paivio A, Spencer LJ, Durkin A, Borgna G, Convertino C, Machmer E. Don't Assume Deaf Students are Visual Learners. J Dev Phys Disabil 2017; 29(1): 153-171.

2. Luft P. Reading Comprehension and Phonics Research: Review of Correlational Analyses with Deaf and Hard-ofHearing Students. J Deaf Stud Deaf Educ 2018; 23 : 148-163.

3. Stephens CB, Prosser DJ, Pantin-Jackwood MJ, Berlin $A M$, Spackman E. The Pathogenesis of H7 Highly Pathogenic Avian Influenza Viruses in Lesser Scaup (Aythya affinis). Avian Dis 2019; 63: 230-234.

4. Flood E, Boiteux C, Lev B, Vorobyov I, Allen TW. Atomistic Simulations of Membrane Ion Channel Conduction, Gating, and Modulation. Chem Rev 2019; 119: 7737-7783.

5. Wangemann $P$, Nakaya $K, W u$ T, Itza EM, Sanneman $J D$, Sanneman JD, Harbidge DG, Billings $S$, Marcus DC. Loss of cochlear HCO3- secretion causes deafness via endolymphatic acidification and inhibition of $\mathrm{Ca} 2+$ reabsorption in a Pendred syndrome mouse model. Am J Physiol Renal Physiol 2017; 292(5): 1345-1353.

6. Su XD, Gao ZG, Bao Y, Guan M, Rohani S, Yin QX, Hao $H X$, Xie C, Wang JK. Gelation Mechanism of Erythromycin Ethylsuccinate During Crystallization. Trans Tianjin Univ 2018; 25: 110-117.

7. World Health Organization. Principles of laboratory animal care. WHO Chron 1985; 39: 51-56.

8. Zhao L. Observation of "Integration of Breath, Blood and Voice" Acupoint Control Singing to Rehabilitate Senile Dementia and Degenerative Deafness Cases. Am Tradit Chin Med: Eng Version 2017; 14: 141.

9. Pepermans E, Petit C. The tip-link molecular complex of the auditory mechano-electrical transduction machinery. Hear Res 2015; 330: 10-17.

10. Fu Y, Ding D, Wei L, Jiang H, Salvi R. Ouabain-Induced Apoptosis in Cochlear Hair Cells and Spiral Ganglion Neurons In Vitro. Biomed Res Int 2013; 10: 628064.

11. Shabbir MZ, Quan Y, Wang Z, Bravo A, Soberón M, He $K$. Characterization of the Cry1Ah resistance in Asian corn Borer and its cross-resistance to other Bacillus thuringiensis toxins. Sci Rep 2018; 8(1): 234.

12. Bone RN, Gai Y, Magrioti V, Kokotou MG, Ali T, Lei $X$, Tse HM, Kokotos G, Ramanadham S. Inhibition of Ca2+-independent phospholipase A2 $\hat{l}^{2}$ (iPLA2 $\left.\hat{l}^{2}\right)$ ameliorates islet infiltration and incidence of diabetes in NOD mice. Diabetes 2015; 64(2): 541-554.

13. Mellas RE, Leigh NJ, Nelson JW, McCall AD, Baker OJ. ZO-1, Occludin, and E-cadherin Expression and Organization in Salivary Glands with Sjogren's syndrome. J Histochem Cytochem 2016; 63(1): 45-56.

14. Liu X, Xie Y, Huang S, Xu A, Zhao M, Kang X, Yan A, Li $P$, Jin $C$, Han F. Characterization of the early pathology of cochlear stereocilia in four inbred mouse strains with progressive hearing loss. Histol Histopathol 2019; 34(7): 811-820.

15. Soyfoo MS, Chivasso C, Perret J, Delporte C. Involvement of Aquaporins in the Pathogenesis, Diagnosis and Treatment of Sjögren's Syndrome. Int J Mol Sci 2018; 19(11): 3392.

16. Fu QQ, Ge QF, Liu R, Wang HO, Zhou GH, Zhang WG. Influence of modified atmosphere packaging on protein oxidation, calpain activation and desmin degradation of beef muscles. J Sci Food Agric 2017; 97(13): 45084514. 